\title{
Distorted Retrospective Eyewitness Reports as Functions of Feedback and Delay
}

\author{
Gary L. Wells, Elizabeth A. Olson, and Steve D. Charman \\ Iowa State University
}

\begin{abstract}
Participant-witnesses viewed a crime video and attempted to identify the culprit from a culprit-absent lineup. The 253 mistaken-identification eyewitnesses were randomly given confirming, disconfirming, or no feedback regarding their identifications. Feedback was immediate or delayed $48 \mathrm{hr}$, and measures were immediate or delayed $48 \mathrm{hr}$. Confirming, but not disconfirming, feedback led to distortions of eyewitnesses' recalled confidence, amount of attention paid during witnessing, goodness of view, ability to make out facial details, length of time to identification, and other measures related to the witnessing experience. Unexpectedly, neither delaying the measures nor delaying feedback for $48 \mathrm{hr}$ moderated these effects. The results underscore the need for double-blind lineups and neutral assessments of eyewitnesses' certainty and other judgments prior to feedback.
\end{abstract}

Although courts have long been concerned with what an eyewitness might be told before viewing a lineup, courts have not shown concern for what an eyewitness might be told after he or she makes an identification (Wells et al., 1998). This is understandable to the extent that courts are focused only on how suggestive procedures might affect the identification decision itself. After all, the identification has already happened, and anything said after the identification could not work backward to influence it. This narrow focus on the identification itself, however, overlooks the profound influence that postidentification suggestions have on the testimony that the eyewitness might later give about the identification. Particularly important is the confidence that the eyewitness recalls having had in his or her identification, what the eyewitness later says about the witnessing conditions, and other testimonial reconstructions that the eyewitness gives of the event. Postidentification feedback from the lineup administrator (e.g., "Good, you identified the suspect" or "No, that person was just a lineup filler") has powerful and broad effects on how the eyewitness recalls the original event and on how the eyewitness recalls the identification decision, an effect called the postidentification feedback effect.

The original experiments demonstrating the postidentification feedback effect (Wells \& Bradfield, 1998) had participantwitnesses identify a person from a culprit-absent lineup; hence, all identifications were mistaken. Participant-witnesses were then randomly assigned to receive confirming feedback ("Good, you identified the suspect"), disconfirming feedback ("Actually, the suspect was Number _," which was a lineup member not chosen by the eyewitness), or no feedback at all. Relative to those who received no feedback, those who received confirming feedback inflated their recollections of certainty, and those who received

Gary L. Wells, Elizabeth A. Olson, and Steve D. Charman, Psychology Department, Iowa State University.

This research was supported by National Science Foundation Grant SBR9807339 to Gary L. Wells.

Correspondence concerning this article should be addressed to Gary L. Wells, Psychology Department, Iowa State University, Ames, Iowa 50011. E-mail: glwells@iastate.edu disconfirming feedback deflated their recollections of certainty. Secondary accounts of the postidentification feedback effect usually refer only to the effect of postidentification feedback on retrospective confidence. However, postidentification feedback affects not only retrospective reports of confidence, but also eyewitnesses' retrospective reports of how good their view was, how much attention they paid to the culprit while witnessing the event, how long they took to make the identification decision, how well they could make out details of the culprit's face, how easy it was to make the identification decision, and other measures. Collectively, we refer to these various measures as retrospective reports of the witnessing experience. Any psychological interpretations of the postidentification feedback effect must take into account this broad range of effects on retrospective reports of the witnessing experience rather than merely the effect on retrospective confidence.

Recent studies have replicated and extended the postidentification feedback effect in various ways. For example, the postidentification feedback effect is reduced by having eyewitnesses think privately about their certainty, the view they had, and so on, prior to giving them feedback (Wells \& Bradfield, 1999). In addition, the postidentification feedback effect also applies to eyewitnesses who make accurate identifications, although the effect is stronger for those who make inaccurate identifications (Bradfield, Wells, \& Olson, 2002). Recent experiments also indicate that the postidentification feedback effect works for nonidentifications (e.g., "not there" responses) as well as for identifications (Semmler, Brewer, \& Wells, 2002).

It would be difficult to overstate the practical importance of the postidentification feedback effect. The confidence of an eyewitness is the primary factor determining whether people believe that the eyewitness made an accurate identification (e.g., Cutler, Penrod, \& Dexter, 1990; Fox \& Walters, 1986; Wells, Ferguson, \& Lindsay, 1981). Furthermore, the certainty of the eyewitness has been enshrined by the U.S. Supreme Court as a primary factor for judges to consider in deciding whether the identification by an eyewitness is accurate (Manson v. Braithwaite, 1977; Neil v. Biggers, 1972). More important, in the Biggers and Braithwaite 
cases, the Court also endorsed the idea that what the eyewitness says about his or her view and what the eyewitness says about how much attention was paid to the culprit at the time of witnessing are central factors in deciding whether the eyewitness identification was accurate. The fact that all these factors (confidence, view, attention) are malleable as a function of postidentification feedback is a serious concern. In effect, mistaken eyewitnesses can be made to appear very credible simply by telling the eyewitnesses that they identified the right person from a lineup. Lineups, especially photographic lineups - the most common lineups used in the United States - are routinely conducted by the case detective, and feedback to the eyewitness is common (Wells, 1993). Therefore, the status of these variables (confidence, view, attention) as markers of accuracy is undermined by the allowance of feedback. Eyewitnesses who are confident, say they had a good view, and say they paid close attention to the culprit at the time of witnessing might be accurate witnesses, or they might be inaccurate witnesses who were given confirming feedback.

The reliability of the postidentification feedback effect is well established (over 1,150 participant-witnesses have been tested), and the size of the postidentification feedback effect is large (over a full standard deviation in some conditions). Nevertheless, one feature of every experiment published thus far is that feedback has always been delivered to the eyewitnesses almost immediately after they made their identifications. In none of the postidentification feedback effect experiments has the feedback been delayed more than $3 \mathrm{~min}$ after the eyewitnesses made their lineup decisions. In addition, the dependent measures in these experiments have always been administered almost immediately after the feedback, in no case exceeding $3 \mathrm{~min}$.

There are both theoretical and practical reasons to consider the amount of time between identification and feedback and the amount of time between feedback and dependent measures to be critical. From a practical perspective, these delay intervals can and do vary in actual cases. From a theoretical perspective, there are reasons to think that these delay intervals may affect whether or not the postidentification feedback effect occurs, or at least may affect the magnitude of the postidentification feedback effect.

\section{Practical Reasons to Study Delay}

Thus far, experiments on the postidentification feedback effect have contrasted conditions in which the eyewitness receives feedback or not immediately after the identification decision, and the effects are assessed immediately after the manipulation of feedback. This simulates real-world conditions in which the lineup administrator reacts almost immediately to the eyewitness's decision and then assesses the eyewitness's certainty at the time the lineup is conducted. Suppose, however, the lineup administrator does not react to the eyewitness's identification decision and, instead, the eyewitness gets feedback at a later time. The Federal Bureau of Investigation, for instance, is now using an identification procedure in which the agent is prohibited from telling the eyewitness anything about the status of the person the eyewitness identifies, but no confidence statement is secured from the eyewitness at that time. The eyewitness might then get feedback at a later time (e.g., on a ride home from the police station, in a later interview with an agent, in a prehearing briefing from a prosecu- tor). Does feedback still have its effects when the feedback is delayed?

Another real-life scenario that may occur is when the feedback occurs immediately but the confidence of the eyewitness is not assessed on the day of the lineup. Instead of asking eyewitnesses at the time of the identification how confident they are in their identification decision, they may not be asked such a question until they are interviewed by a prosecutor or, in some cases, until they are deposed at a pretrial hearing. Does feedback received at the time of the identification affect responses at a later time?

\section{Theoretical Reasons Why Delay Might Matter}

Wells and Bradfield (1999) proposed that the postidentification feedback effect results from participant-witnesses using the feedback to infer answers to questions about their witnessing experience. According to Wells and Bradfield, the reason witnesses rely on the inference process, rather than directly recalling the witnessing experience, is because they have weak memories of their witnessing experience. In other words, eyewitnesses do not form online memory traces for how confident they were at the time of the identification, how good their view was of the culprit, how much attention they paid at the time of witnessing, and so on. As a result, eyewitnesses construct answers based on the feedback (e.g., "I must have had a good view because I apparently identified the right person"). Evidence supporting this interpretation comes from conditions in which participant-witnesses' memories for their witnessing experience were made salient prior to the feedback manipulation. After making their identification decision, but prior to feedback, participant-witnesses were required to think privately (for $3 \mathrm{~min}$ ) about how confident they were, how good their view was, and how much attention they paid to the culprit. The private-thought manipulation largely erased the postidentification feedback effect. Presumably, priming witnesses to think about their confidence, view, and so on before the feedback prompted them to develop a memory trace for their prefeedback opinions on these matters, which they could then draw on after getting feedback. This interpretation of the postidentification feedback effect is consistent with the idea that people construct answers to questions at the time they are asked, especially when they had not thought much about the issue until they were asked (Schwarz, 1999).

We expected the passage of time between identification and feedback to have the same moderating effect that the 3-min private-thought manipulation had in the Wells and Bradfield (1999) experiment. The idea is that participant-witnesses simply have not had enough time after their identification to think on their own about their witnessing experience before they received feedback. Because they were given feedback immediately after the identification, they have no prefeedback thoughts about the witnessing experience because they have not had time to have such thoughts. In the current experiment, feedback was delayed for 48 hr for some participant-witnesses, and we expected this delay to moderate the effect of feedback.

However, there are theoretical reasons to believe that the postidentification feedback effect may be even stronger when feedback is delayed than when it is not delayed. Specifically, we may expect that witnesses' direct memories for their witnessing experience would be weaker after $48 \mathrm{hr}$ than they were immediately after the 
lineup, making witnesses even more dependent on the feedback than they were $48 \mathrm{hr}$ earlier. "Recall is an active, constructive process that is guided by people's knowledge at the time of retrieval" (Ross, 1989), and the longer one waits until attempting to recall, the more we would expect current knowledge to shape recall. In general, the weaker the memory for the event in question, the more dependent respondents are on contextual factors in responding to questions about that event (Schwarz, 1999).

What about conditions in which feedback is immediate but the effects of feedback are not measured until $48 \mathrm{hr}$ later? Research on suggestion effects has shown that the passage of time after the suggestion can result in a "lifting" of the interfering effects of suggestion. For example, Windschitl (1996) had participants view a series of faces. Then, participants were shown some interpolated faces that were similar to the old faces, with labels suggesting that the interpolated faces were the same as the old faces. Participants were then shown a larger set of faces and asked to pick only those that were in the original set. Using an immediate test format, participants mistakenly identified the interpolated faces as being those from the original set. When tested after $48 \mathrm{hr}$, however, the effects of the suggestion were not present. Similar results showing release from suggestion effects have been observed by other researchers (e.g., Chandler, 1991). Windschitl argued that the suggestion temporarily blocks access to the original memory but, with the passage of time, the original memory spontaneously recovers because memory for the suggestion fades faster than for the original memory. Perhaps feedback, which can be considered a form of suggestion, operates in a similar fashion. Although feedback may initially block access to the witness's memory for their witnessing experience, there may be recovery of these memories with the passage of time. According to this spontaneous-recoveryfrom-suggestion account, the postidentification feedback effect should diminish with the passage of time between feedback and measures.

Although there are plausible reasons to believe that a delay between feedback and the taking of measures could make the postidentification feedback effect weaker, we expected this delay to make the postidentification feedback effect even stronger. One of the assumptions behind the spontaneous-recovery-fromsuggestion effect is that memory for the suggestion fades more rapidly with time than does the original memory. In the case of the postidentification feedback effect, however, the original memory of the witnessing experience is presumed to be quite weak from the outset, whereas the feedback is quite salient. Rumination over the feedback could make memory for the feedback fade less rapidly than the memory for the witnessing experience, resulting in an even stronger postidentification feedback effect if there is a delay than if there is no delay between feedback and measures.

In addition to the theoretical implications of learning what happens to the postidentification feedback effect under these delay conditions, there are important practical implications. If the postidentification feedback effect is enhanced or maintained under delay, then previous recommendations (Wells et al., 1998) regarding double-blind lineup procedures and immediate assessments of confidence are reinforced. However, if the postidentification feedback effect is eliminated or diminished under delay, then possible alternatives to double-blind lineups and immediate assessments of confidence can be proposed.

\section{Overview}

After viewing a staged crime video, participant-witnesses were asked to identify the culprit from a six-person photographic lineup. Unaware that the lineup did not contain the culprit, all witnesses identified someone. Participants were then randomly assigned to receive confirming feedback, no feedback, or disconfirming feedback, either in the current session or $48 \mathrm{hr}$ later. In addition, measures of retrospective confidence, view, attention, and other questions about the witnessing experience were administered to witnesses either in the current session or $48 \mathrm{hr}$ later.

\section{Method \\ Participants and Design}

Participants were 253 students who were randomly assigned to conditions and received a small credit toward their course grade for participation. The design involved three levels of the feedback variable: no feedback, confirming feedback, or disconfirming feedback. In addition, there were three levels of the delay variable: immediate feedback with immediate measures, immediate feedback with delayed measures, or delayed feedback with delayed measures. We crossed the feedback variable with the delay variable so that we could test the effects of feedback for each type of delay. Notice, however, that the resulting design is not a 3 (feedback) $\times 3$ (delay) factorial because two of the conditions are actually the same condition. Specifically, the immediate-no-feedback-with-delayed measures condition and the delayed-no-feedback-with-delayed measures condition are identical because, of course, giving no feedback immediately or giving no feedback later is the same nonevent. Accordingly, the design has eight, not nine conditions. Because no feedback with delayed measures is the control condition for both the immediate-feedback-with-delayed measures condition and for the delayed-feedback-with-delayed measures condition, we doubled the sample size for the no-feedback-with-delayed measures condition. The resulting design is shown in Table 1 . We refer to this table later in the Results section to describe the planned contrasts that we used in our analyses.

Participants in all conditions returned after $48 \mathrm{hr}$, even those who completed the measures on Day 1. Those who completed measures on Day 1 (all three immediate-measures conditions) completed the same measures again on Day 2. These participants' Day 2 data were not included in the main analyses, but we analyzed their data to determine whether there were any significant shifts in their answers from Day 1 to Day 2. A 3 (confirming feedback with immediate measures, disconfirming feedback with immediate measures, no feedback with immediate measures) $\times 2$ (repeated measures Day 1 vs. Day 2) analysis of variance (ANOVA) revealed no main effect on the confidence measure for Day 1 versus Day 2 and no interaction between day and feedback condition, $F \mathrm{~s}(2,80)=0.59$ and $1.54, n s$, respectively. Furthermore, the correlations between Day 1 and Day 2 on the confidence measure were $.94, .88$, and .85 for the nofeedback, confirming-feedback, and disconfirming-feedback conditions, respectively. Hence, there was strong reliability in the participants' answers over the 48-hr period.

\section{Materials}

Video event. The witnessed event was a videotaped scene ${ }^{1}$, lasting approximately $60 \mathrm{~s}$. The scene was shot from the perspective of a person who enters an office setting, looks around at a desk, computer, and papers, and then focuses through a window. Outside the window and approximately $15 \mathrm{ft}(4.0 \mathrm{~m})$ away from it is a roof on which a man is standing and

${ }^{1}$ The video can be viewed at the following Internet address: http:// 129.186.143.73/faculty/gwells/theeyewitnesstest.html 
Table 1

The Experimental Design and Planned Contrasts

\begin{tabular}{|c|c|c|c|c|c|c|c|c|c|}
\hline \multirow{2}{*}{$\begin{array}{l}\text { Type of } \\
\text { feedback }\end{array}$} & \multirow{2}{*}{$\begin{array}{l}\text { Time of } \\
\text { feedback }\end{array}$} & \multirow{2}{*}{$\begin{array}{l}\text { Time of } \\
\text { measures }\end{array}$} & \multicolumn{7}{|c|}{ Planned Contrasts } \\
\hline & & & 1 & 2 & 3 & 4 & 5 & 6 & 7 \\
\hline Confirming & Immediate & Immediate & $1 / 3$ & & & & -1 & & \\
\hline Confirming & Immediate & Delayed & $1 / 3$ & & & -1 & 1 & & \\
\hline Confirming & Delayed & Delayed & $1 / 3$ & & & 1 & & & \\
\hline Disconfirming & Immediate & Immediate & & $1 / 3$ & & & & & 1 \\
\hline Disconfirming & Immediate & Delayed & & $1 / 3$ & & & & -1 & -1 \\
\hline Disconfirming & Delayed & Delayed & & $1 / 3$ & & & & 1 & \\
\hline None & & Immediate & $-1 / 2$ & $-1 / 2$ & -1 & & 1 & & -1 \\
\hline None & & Delayed & $-1 / 2$ & $-1 / 2$ & 1 & & -1 & & 1 \\
\hline
\end{tabular}

Note. Contrast $1=$ Was there an effect for confirming versus no feedback collapsed over delay?; Contrast $2=$ Was there an effect for disconfirming versus no feedback collapsed over delay?; Contrast $3=$ Did delay of measures matter in the absence of feedback?; Contrast $4=$ Did delay of confirming feedback matter?; Contrast $5=$ Did delay of measures moderate the effect of confirming feedback?; Contrast $6=$ Did delay of disconfirming feedback matter?; Contrast $7=$ Did delay of measures moderate the effect of disconfirming feedback?

the camera zooms to focus $6 \mathrm{ft}(1.8 \mathrm{~m})$ from the man's face. The man is manipulating a large object into an air shaft, looks up toward the window, appears to realize he is being watched, drops the object down the air shaft, and runs toward a rooftop door. The video then captures a view of the man coming through the rooftop door, past the camera, and down a set of stairs. The man on the roof is hereafter called the rooftop bomber for purposes of this article. The rooftop bomber was a 21-year-old man with short, dark hair, a medium build, and no facial hair.

Lineup. The lineup was a six-person photo $\operatorname{array}^{2}$ that did not include the rooftop bomber. All members of the lineup fit the general description of the rooftop bomber, but none were an extremely close resemblance to him.

Primary dependent measures. The dependent-measures booklet was divided into two main sections. The first 10 questions included postidentification feedback effect questions used in previous studies (Bradfield et al., 2002; Wells \& Bradfield, 1998, 1999), hereafter called the primary measures. The 10 primary questions are listed in Table 2 in the order in which they originally appeared. The next 7 questions were exploratory and concerned self-reports of the process by which the participants made their identification decisions. The 7 exploratory questions are also listed in Table 2 in the order in which they originally appeared. A final question asked participants whether the feedback they received influenced how they answered the confidence question. This question required a yes or no answer.

\section{Procedure}

Participants signed up to participate in a study titled "Impressions of People." They were not told it was a study of eyewitness identification, but instead were told only that the study involved viewing a video and answering some questions. At the time that participants signed up, they committed themselves to participating in two sessions; each of which could last up to $50 \mathrm{~min}$ and were $48 \mathrm{hr}$ apart. Hence, participants who signed up for 2:00 p.m. on Tuesday knew that they would have to return at 2:00 p.m. on Thursday, and so on. As many as 2 participants could sign up for a given session. Approximately half the sessions had 1 person and half had 2 persons.

Day 1. On arrival, participants were told that the study involved impressions of people and were directed to a cubicle with a television monitor. When there were 2 participants, each was directed to an individual cubicle. They were told to pay attention to the short video because they would be asked questions about it later. The experimenter was not present when the video was shown. Following the video, the experimenter reentered the cubicle and informed the participant that she or he had just witnessed someone planting a bomb in an air shaft and that the study concerned their ability to identify the rooftop bomber from a lineup. The experimenter then showed the participant-witness the six-person photo array and asked him or her to "Identify the person you saw plant the bomb." The experimenter waited for the witness to make a choice. If the witness was reluctant to make a choice, the experimenter encouraged him or her ("Just try to pick out the person as best you can").

When the witness made a choice, the experimenter recorded the choice and then consulted a random-assignment sheet to determine whether there was to be feedback or not at this time. In the no-feedback and delayedfeedback conditions, the experimenter simply acknowledged the number that the witness identified by saying "OK ... you identified Number [whatever number the witness identified]. I'll be back in a few minutes." In the immediate-feedback conditions, the experimenter gave either confirming or disconfirming feedback at that point. Confirming-feedback witnesses were told "OK ... you identified Number [whatever number the witness identified]. Good, [pause] you identified the actual suspect. I'll be back in a few minutes." In the disconfirming-feedback conditions, the witnesses were told "OK ... you identified Number [whatever number the witness identified]. Well, the actual suspect was Number [Number 1 if they identified Numbers 2-6 or Number 3 if they identified Number 1]. I'll be back in a few minutes."

The experimenter then exited the cubicle and again consulted a randomassignment chart to determine whether the witness was to fill out the dependent measures at this point or was to have the measures delayed for $48 \mathrm{hr}$. If the witness was to fill out the measures at this point (immediate-measure conditions), the experimenter reentered the cubicle and told the witness that he or she needed to answer some questions about what he or she saw in the video. These participants were then given the written questions, as described in the Materials section. After completing the questions, these witnesses were taken back to the main room where they were reminded of their return appointment. Witnesses in the delayedmeasures conditions were simply told to return to the main room where they were reminded about their follow-up appointment. All participants were told that they would be asked some additional questions about the

\footnotetext{
${ }^{2}$ The photo array, along with a photo of the rooftop bomber, can be viewed at the following Internet address: http://129.186.143.73/faculty/ gwells/bomberandabsentlineup.ppt
} 


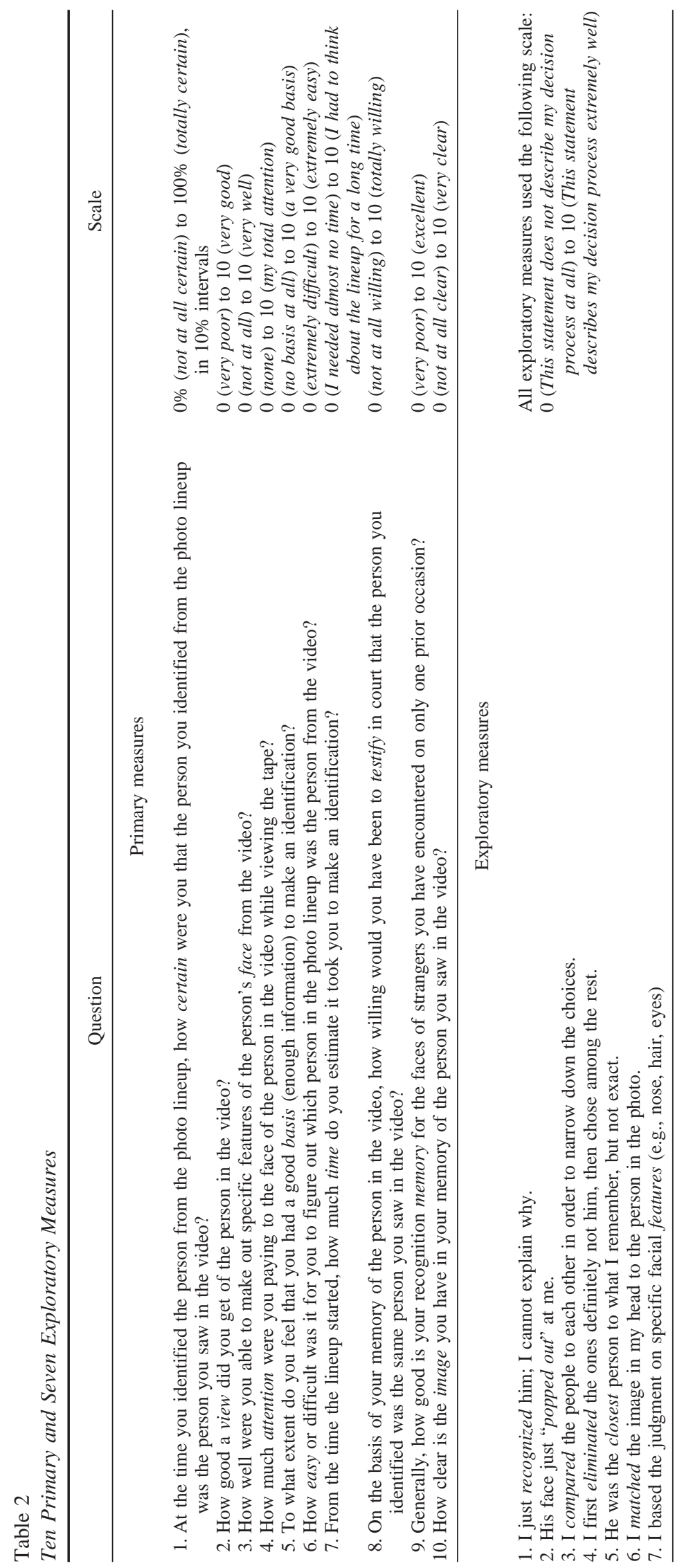


video when they returned and were instructed to not talk with anyone about the study in the interim. The experimenter stressed the importance of returning on Day 2 and obtained some form of commitment (oral commitment, or, at least a head nod) that they would return. Only 3 participants failed to return on Day 2, and their data were not included.

Day 2. On their return, participants were again directed to an individual cubicle. Witnesses who had already filled out the dependent measures on Day 1 were simply given the dependent measures packet again and asked to fill it out. Participants who did not fill out measures on Day 1 (delayed-measures conditions) and who did not receive feedback on Day 1 (delayed-feedback conditions) were then randomly assigned to get confirming, disconfirming, or no feedback on Day 2. The experimenter showed them the photo array again. Witnesses in the no-feedback/delayedmeasures condition were told "OK ... you identified Number [whatever number the witness identified]. I'll be back in a few minutes." Witnesses in the confirming-feedback condition were told "OK ... you identified Number [whatever number the witness identified]. Good, [pause] you identified the actual suspect. I'll be back in a few minutes." Witnesses in the disconfirming-feedback condition were told "OK ... you identified Number [whatever number the witness identified]. Well, the actual suspect was Number [Number 1 if they identified Numbers $2-6$ or Number 3 if they identified Number 1]. I'll be back in a few minutes." The experimenter then exited the cubicle and returned with the written questions, as described in the Materials section. After filling out the dependent measures on Day 2, all participants were fully debriefed.

\section{Results}

\section{Overview of Analyses}

We first report results on the primary measures, then report results on the exploratory measures, and then report analyses on whether the witnesses thought the feedback influenced how they answered the retrospective-confidence question. For the primary measures, we conducted one-way between-subjects ANOVAs across the eight cells. If the one-way ANOVA was significant, we then used the error term for the ANOVAs to conduct seven single-degree-of-freedom planned contrasts. Table 1 details the seven contrasts. Contrast 1 assesses the overall effect for confirming feedback relative to no feedback collapsed over both types of delay. Contrast 2 assesses the overall effect for disconfirming feedback relative to no feedback collapsed over the delay variables. Contrast 3 tests whether there was an effect for delay of measures in the absence of any feedback. Contrast 4 tests whether there was an effect for delay of confirming feedback. Contrast 5 tests whether the delay of measures moderated the effects of confirming feedback. Contrast 6 tests whether there was an effect for delay of disconfirming feedback. Contrast 7 tests whether the delay of measures moderated the effects of disconfirming feedback. We conducted all tests using the .01 level of significance and used Cohen's $d$ to calculate effect size for each single-degree-offreedom test. For the exploratory measures, we also conducted a one-way ANOVA across the eight cells. If the one-way ANOVA was significant on an exploratory measure, we then conducted the first three single-degree planned contrasts described in Table 1. As with the primary measures, we conducted all tests for the exploratory measures using the .01 level of significance and used Cohen's $d$ to calculate effect size for each single-degree-of-freedom test.

\section{Primary Measures}

Table 3 shows the within-cell correlations among the 10 primary measures (the time measure was reverse-scored). Because these measures were highly correlated, we conducted a factor analysis to determine whether one factor explained a sufficient amount of variance to combine the measures into a single score. We did not include confidence in this factor analysis, however, because there are literature-based reasons for examining the confidence measure alone rather than combining it with the other measures. Specifically, other than accuracy, confidence is the most studied dependent variable in the eyewitness identification literature and is widely considered to have more impact than any other variable on the perceived accuracy of eyewitness identification testimony (Wells, Olson, \& Charman, 2002). Accordingly, we wanted to know how the confidence measure was behaving as a function of the manipulations rather than collapsing it with the other measures. A factor analysis on the remaining nine primary measures showed that a single-factor solution accounted for $51 \%$ of the variance (eigenvalue $=5.1$ ). A two-factor solution accounted for only $12 \%$ additional variance (eigenvalue $=1.2$ ). Accordingly, we combined these nine primary measures into a single score for purposes of analysis. Means and standard deviations for all 10 primary measures and the combined measure are shown in Table 4.

Confidence. The one-way ANOVA on the confidence measure indicated significant differences across the eight conditions, $F(7$, $245)=10.73, p<.01, M S E=6.33$, Cohen's $f=0.82$. Using the mean square error from this ANOVA, we conducted the planned contrasts, as indicated in Table 1 . The results showed that

Table 3

Correlations Between the 10 Primary Measures

\begin{tabular}{|c|c|c|c|c|c|c|c|c|c|c|}
\hline Measure & 1 & 2 & 3 & 4 & 5 & 6 & 7 & 8 & 9 & 10 \\
\hline 1. Confidence & - & $.49 *$ & $.49 *$ & $.44 *$ & $.67 *$ & $.74 *$ & $.41 *$ & $.68^{*}$ & $.36^{*}$ & $.49 *$ \\
\hline 2. View & & - & $.75^{*}$ & $.46^{*}$ & $.61 *$ & $.44 *$ & $.17 *$ & $.39 *$ & $.24 *$ & $.42 *$ \\
\hline 3. Face & & & - & $.49 *$ & $.58^{*}$ & $.44 *$ & $.18^{*}$ & $.41^{*}$ & $.22 *$ & $.48^{*}$ \\
\hline 4. Attention & & & & - & $.55^{*}$ & $.40^{*}$ & .16 & $.45^{*}$ & $.40 *$ & $.56^{*}$ \\
\hline 5. Basis & & & & & - & $.64 *$ & $.28 *$ & $.62 *$ & $.40 *$ & $.49 *$ \\
\hline 6. Ease & & & & & & - & $.52 *$ & $.60^{*}$ & $.35^{*}$ & $.42 *$ \\
\hline 7. Time & & & & & & & - & $.32 *$ & .13 & $.21 *$ \\
\hline 8. Testify & & & & & & & & - & $.41 *$ & $.50 *$ \\
\hline 9. Memory & & & & & & & & & - & $.46^{*}$ \\
\hline 10. Image & & & & & & & & & & - \\
\hline
\end{tabular}




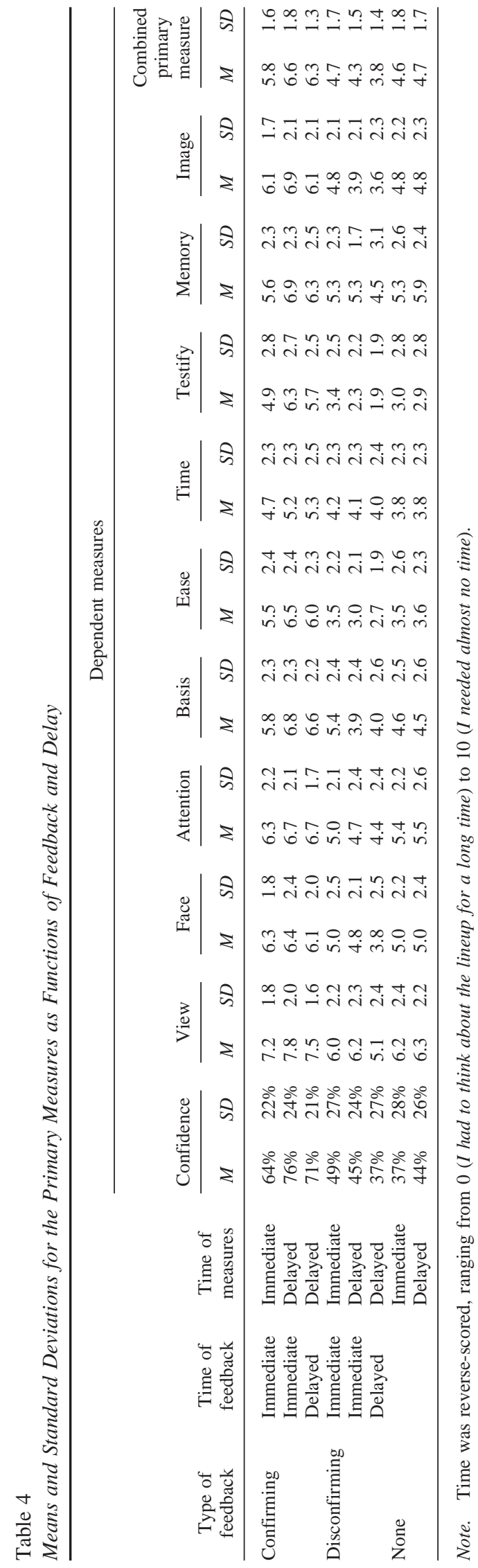

confirming feedback yielded significantly higher retrospective confidence than did no feedback when collapsed over the delay variables (Contrast 1$), t(245)=7.50, p<.01, d=1.19$. Disconfirming feedback, however, did not yield significantly lower retrospective confidence than no feedback when collapsed over the delay variables (Contrast 2), $t(245)=0.82, n s, d=0.13$. Delay of measures in the absence of feedback had no significant effect on confidence (Contrast 3), $t(245)=1.14, n s, d=0.28$. Delay of confirming feedback had no significant effect, and delay of measures did not significantly moderate the effect of confirming feedback (Contrasts 4 and 5), $t \mathrm{~s}(245)=0.74,0.61, n s, d \mathrm{~s}=0.20$ and 0.20 , respectively. Similarly, delay of disconfirming feedback had no significant effect, and delay of measures did not significantly moderate the effect of disconfirming feedback (Contrasts 6 and 7), $t \mathrm{~s}(245)=1.32,1.11, n s, d \mathrm{~s}=0.32$ and 0.44 , respectively.

Combined primary measure. The one-way ANOVA on the combined measure indicated significant differences across the eight conditions, $F(7,249)=11.48, p<.01, M S E=2.59$, Cohen's $f=0.57$. Using the mean square error from this ANOVA, we conducted the planned contrasts, as indicated in Table 1 . The results showed that confirming feedback yielded significantly higher scores on the combined measure than did no feedback when collapsed over the delay variables (Contrast 1$), t(249)=6.26, p<$ $.01, d=0.98$. Disconfirming feedback, however, did not yield significantly different scores on the combined measure relative to no feedback when collapsed over the delay variables (Contrast 2), $t(249)=1.62, n s, d=0.24$. Delay of measures in the absence of feedback had no significant effect on the combined measure (Contrast 3), $t(249)=0.22, n s, d=0.06$. Delay of confirming feedback had no significant effect, and delay of measures did not significantly moderate the effect of confirming feedback on the combined measure (Contrasts 4 and 5 ), $t \mathrm{~s}(249)=0.75,1.22, n s$, $d \mathrm{~s}=0.19$ and 0.43 , respectively. Similarly, delay of feedback had no significant effect, and delay of measures did not significantly moderate the effect of disconfirming feedback on the combined measure (Contrasts 6 and 7), $t(249)=1.15,0.99, n s, d s=0.31$ and 0.31 , respectively.

\section{Exploratory Measures}

Means and standard deviations for the seven exploratory measures are shown in Table 5. Unlike the primary measures, a factor analysis on the exploratory measures did not produce a good one-factor solution. A single-factor solution accounted for only $27 \%$ of the variance (eigenvalue $=1.9$ ), and a two-factor solution accounted for an additional $26 \%$ of the variance (eigenvalue $=1.8$ ). Accordingly, we did not create a single composite score for the seven exploratory measures. Also, whereas our interest in the primary measures concerned whether the feedback effect was moderated by the delay variables, our interest in the exploratory measures was whether feedback would influence how participants answered these questions at all. Hence, we conducted one-way ANOVAs across the eight cells for each of the seven exploratory questions. When the one-way ANOVA was significant, we conducted three single-degree-of-freedom contrasts corresponding to the first three contrasts listed in Table 1.

We observed significant one-way ANOVAs for four of the seven exploratory measures; namely, the recognized question, $F(7$, $248)=24.10, p<.01, M S E=6.35$, Cohen's $f=0.58$; the popped 
Table 5

Means and Standard Deviations for the Seven Exploratory Measures as Functions of Feedback and Delay

\begin{tabular}{|c|c|c|c|c|c|c|c|c|c|c|c|c|c|c|c|c|}
\hline \multirow{3}{*}{$\begin{array}{l}\text { Type of } \\
\text { feedback }\end{array}$} & \multirow{3}{*}{$\begin{array}{l}\text { Time of } \\
\text { feedback }\end{array}$} & \multirow{3}{*}{$\begin{array}{l}\text { Time of } \\
\text { measures }\end{array}$} & \multicolumn{14}{|c|}{ Dependent measures } \\
\hline & & & \multicolumn{2}{|c|}{ Recognized } & \multicolumn{2}{|c|}{$\begin{array}{l}\text { Popped } \\
\text { out }\end{array}$} & \multicolumn{2}{|c|}{ Compared } & \multicolumn{2}{|c|}{ Eliminated } & \multicolumn{2}{|c|}{ Closest } & \multicolumn{2}{|c|}{ Matched } & \multicolumn{2}{|c|}{ Features } \\
\hline & & & $M$ & $S D$ & $M$ & $S D$ & $M$ & $S D$ & $M$ & $S D$ & $M$ & $S D$ & $M$ & $S D$ & $M$ & $S D$ \\
\hline \multirow{3}{*}{ Confirming } & Immediate & Immediate & 4.7 & 2.9 & 4.2 & 2.7 & 5.4 & 3.2 & 6.3 & 3.1 & 7.5 & 2.6 & 7.0 & 2.6 & 6.3 & 2.4 \\
\hline & Immediate & Delayed & 4.7 & 2.8 & 4.4 & 2.7 & 5.8 & 3.0 & 6.3 & 2.6 & 5.4 & 2.9 & 7.3 & 1.9 & 6.7 & 2.7 \\
\hline & Delayed & Delayed & 5.0 & 2.6 & 5.6 & 2.7 & 5.8 & 2.8 & 6.1 & 3.2 & 6.4 & 3.1 & 7.3 & 2.3 & 6.9 & 2.7 \\
\hline \multirow{3}{*}{ Disconfirming } & Immediate & Immediate & 3.8 & 2.5 & 4.3 & 2.6 & 6.6 & 2.5 & 7.0 & 2.3 & 5.8 & 2.4 & 6.2 & 2.1 & 6.7 & 2.1 \\
\hline & Immediate & Delayed & 3.5 & 1.9 & 2.9 & 2.2 & 7.4 & 2.0 & 8.2 & 1.7 & 6.7 & 2.4 & 6.1 & 2.5 & 5.1 & 3.3 \\
\hline & Delayed & Delayed & 2.7 & 2.2 & 3.0 & 2.2 & 6.3 & 2.7 & 7.0 & 2.7 & 7.1 & 2.2 & 4.9 & 2.7 & 4.8 & 3.1 \\
\hline \multirow[t]{2}{*}{ None } & & Immediate & 2.6 & 2.3 & 2.6 & 2.5 & 6.2 & 3.1 & 6.6 & 2.8 & 7.2 & 2.5 & 5.9 & 2.7 & 5.5 & 3.0 \\
\hline & & Delayed & 3.7 & 2.7 & 3.6 & 2.4 & 6.1 & 2.8 & 6.5 & 2.8 & 7.3 & 2.4 & 6.0 & 2.5 & 6.0 & 2.7 \\
\hline
\end{tabular}

out question, $F(7,248)=30.47, p<.01, M S E=6.19$, Cohen's $f=0.61$; the close question, $F(7,247)=17.79, p<.01$, $M S E=6.48$, Cohen's $f=0.95$; and the matched question, $F(7$, 247) $=19.45, p<.01, M S E=5.97$, Cohen's $f=0.69$. We then conducted the three planned contrasts only on these four questions. For the recognized question, confirming feedback yielded significantly higher endorsement than did no feedback when collapsed over the delay variables (Contrast 1 ), $t(248)=4.16, p<.01$, $d=0.65$; disconfirming feedback did not yield significantly lower endorsement of the recognized question than no feedback when collapsed over the delay variables (Contrast 2), $t(248)=0.43, n s$, $d=0.07$; and delay of measures in the absence of feedback had no significant effect on endorsement of the recognized question (Contrast 3), $t(248)=1.85, n s, d=0.44$. For the popped out question, confirming feedback yielded significantly higher endorsement than did no feedback when collapsed over the delay variables (Contrast 1$), t(248)=4.29, p<.01, d=0.66$; disconfirming feedback did not yield significantly lower endorsement of the popped out question than no feedback when collapsed over the delay variables (Contrast 2), $t(248)=0.80, n s, d=0.12$; and delay of measures in the absence of feedback had no significant effect on endorsement of the popped out question (Contrast 3), $t(248)=1.86, n s, d=0.40$. For the close question, confirming feedback did not produce a significantly higher endorsement than did no feedback (Contrast 1), $t(247)=2.10, n s, d=0.32$; disconfirming feedback did not yield significantly lower endorsement of the close question than no feedback when collapsed over the delay variables (Contrast 2$), t(247)=1.78, n s, d=0.28$; and delay of measures in the absence of feedback had no significant effect on endorsement of the recognized question (Contrast 3), $t(247)=0.28, n s, d=0.04$. Finally, for the matched question, confirming feedback yielded significantly higher endorsement than did no feedback when collapsed over the delay variables (Contrast 1), $t(247)=3.27, p<.01, d=0.51$; disconfirming feedback did not yield significantly lower endorsement of the matched question than no feedback when collapsed over the delay variables (Contrast 2), $t(247)=0.52, n s, d=0.09$; and delay of measures in the absence of feedback had no significant effect on endorsement of the matched question (Contrast 3), $t(247)=0.21$, $n s, d=0.04$.

\section{Self-Reports of Influence From Feedback}

Our final analysis concerned the item that asked witnesses whether they believed that the feedback influenced how they answered the confidence question. This question applied only to the confirming- and disconfirming-feedback conditions. In the disconfirming-feedback conditions, $45 \%$ of the witnesses said that the feedback influenced how they answered the confidence question, and 55\% denied any such influence. In the confirmingfeedback conditions, only 35\% said that feedback influenced how they answered the confidence question, and $65 \%$ denied any such influence. The tendency for disconfirming-feedback witnesses to be more likely than confirming-feedback witnesses to say that feedback influenced them is interesting because the disconfirmingfeedback witnesses were not actually influenced by feedback, whereas the confirming-feedback witnesses were heavily influenced by it. More telling, perhaps, is the difference in confidence scores between confirming- and disconfirming-feedback witnesses who denied that feedback influenced them. The mean confidence for confirming versus disconfirming feedback among witnesses who said feedback influenced them was 7.6 and 4.7, respectively. The mean confidence for confirming versus disconfirming feedback among witnesses who denied that feedback influenced them was 6.7 and 4.1, respectively. A contrast analysis indicated that the difference in mean confidence between confirming and disconfirming feedback was not different for those who said that feedback influenced them versus those who said feedback did not influence them, $t(158)=1.66, n s, d=0.26$.

\section{Discussion}

This study was motivated primarily by the question of how delay of feedback and delay of measures would affect the postidentification feedback effect. The results were clear; neither of these types of delay significantly moderated the postidentification feedback effect. Although we had expected that delaying feedback would weaken the postidentification feedback effect, there was no significant weakening of the effect. We had also expected that giving immediate feedback and delaying the measures might strengthen the postidentification feedback effect, but there was no significant increase in the magnitude of the effect from delaying 
the measures. Furthermore, delaying the measures in the absence of any feedback had no significant effect on any of the measures.

There are two important caveats to these conclusions. First, the statistical power of the experiment for detecting a significant moderating influence for the delay variable was modest. Cohen (1988) defined a medium effect size using the $d$ statistic as 0.50 . In our experiment, power for detecting a medium effect size for the moderating influence of delaying the measures was only $60 \%$ at the .01 level of statistical significance. Accordingly, it is possible that a sample much larger than the 253 participants used in this experiment would have yielded some evidence that delay significantly moderates the effect of feedback.

A second caveat to our conclusion that delay did not moderate the feedback effect concerns our operationalization of delay. Although $48 \mathrm{hr}$ is quite long relative to the $2 \mathrm{~min}$ or less used in previous experiments, actual criminal cases can involve months between identification and feedback or between feedback and the giving of testimony. However, these results show that one cannot prevent the distorting effects of postidentification feedback merely by keeping the events pristine at the time of the lineup; distortions can be induced at least $48 \mathrm{hr}$ later.

Although there was no influence of time per se in the absence of feedback on how participant-witnesses answered the questions, we did nothing to attempt to influence, one way or another, what participant-witnesses thought about over the course of the $48 \mathrm{hr}$. Participants knew that they would be asked more questions about the video, but we told them nothing more than that. In actual cases, we might expect that eyewitnesses would retell their stories to families and friends, speculate about other evidence, wonder whether the accused made bail, or myriad other thoughts and activities. These thoughts, personal interactions, and other activities might well lead to changes in confidence and other recollections independently of feedback in actual cases. Hence, although we observed no inflation or deflation of confidence over the $48 \mathrm{hr}$ in the absence of feedback, we are not prepared to argue that such effects will be absent in actual cases.

One surprise in the data was the lack of an effect for disconfirming feedback. Although disconfirming feedback appeared to have an effect in the negative direction in the present study, it did not reach statistical significance. The original postidentification feedback effect studies included disconfirming-feedback conditions and found that disconfirming feedback significantly affected various measures in the opposite direction from confirming feedback relative to a no-feedback control condition (Wells \& Bradfield, 1998). Nevertheless, disconfirming feedback clearly did not have as strong an effect in the negative direction as confirming feedback had in the positive direction in the Wells and Bradfield experiments. Hence, there may be something about disconfirming feedback that makes it less powerful than confirming feedback. Recent work on the hindsight bias, which seems related to the postidentification feedback effect, suggests one possibility. Hoelzl, Kirchler, and Rodler (2002) conducted a field study on Europeans' reactions to the rise and fall of the new Euro currency. The hindsight bias was observed almost exclusively under conditions in which the outcome aligned with the self-serving tendencies of the respondents. For example, when the Euro rose in value, those for whom that was a favorable outcome tended to show the hindsight bias, whereas those for whom that was an unfavorable outcome did not show the hindsight bias. Similar selective hind- sight biases have been observed by Louie and colleagues in individual-decision outcomes and in team-decision outcomes (Louie, 1999; Louie, Curren, \& Harich, 2000). In the case of the postidentification feedback effect, it seems clear that confirming feedback would be a favorable outcome and disconfirming feedback an unfavorable outcome, which could explain why confirming feedback had more effect than did disconfirming feedback.

\section{Practical Implications}

From a practical perspective, the results of this study are clear. Confirming feedback had a large effect on a wide variety of important retrospective judgments by eyewitnesses. Thus, the idea that feedback is a problem if it is given at the time of the identification, but is not a problem (or is a lesser problem) if it occurs later, received absolutely no support. Similarly, the idea that postidentification feedback is a problem if its effects are assessed immediately, but not if its effects are assessed later, received no support. These data raise doubt that the passage of time per se is a significant factor, one way or another, in the postidentification feedback effect. Events that may occur during the passage of time (e.g., reading a newspaper article about the crime, hearing a National Public Radio broadcast about eyewitness unreliability) could moderate the postidentification feedback effect, but time per se, at least within the range we studied, is probably not a critical factor.

These results reinforce the recommendations of the American Psychology-Law Society Scientific Review Subcommittee on eyewitness identification (Wells et al., 1998) that calls not only for double-blind testing at lineups (to prevent either intentional or unintentional feedback), but also calls for securing a confidence statement at the time of the identification (before any postidentification factors can influence the eyewitness's confidence). The U.S. Department of Justice guide for the collection and preservation of eyewitness evidence (Technical Working Group for Eyewitness Evidence, 1999), which was modeled largely after the Wells et al. article, makes a similar recommendation. Clearly, it is not good enough to just avoid giving feedback at the time of the identification; the eyewitness's confidence at that time needs to become a matter of record because the eyewitness is likely to come across some form of feedback at a later time that can still influence him or her.

Confirming feedback, relative to no feedback, not only leads eyewitnesses to inflate recollections of how confident they were at the time of the identification, but also leads them to recall their view as having been better, recall having paid more attention at the time of witnessing, recall having been better able to make out details of the culprit's face, recall having had a better basis for making the identification, recall it having been easier to figure out who the culprit was in the lineup, recall their identification as having taken less time, recall a clearer image of the culprit in their memory, and recall the culprit's face as having "popped out" in the lineup. In addition, confirming feedback leads eyewitnesses to be more willing to testify and report that they have good abilities to recognize strangers. The broad range of these effects of postidentification feedback is perhaps the most intriguing aspect of the postidentification feedback effect. But it also raises a troubling new question regarding recommendations on good identification procedures. Whereas current recommendations have focused on 
the importance of assessing the eyewitness's confidence at the time of the identification, prior to the eyewitness being exposed to any feedback, the question arises as to whether the eyewitness's answers to these other questions (e.g., view, attention, clarity of memory) also ought to be assessed and made a matter of record at the time of the identification rather than later.

Note that these postidentification feedback effects are quite large. Using the effect-size estimate, $d$, Cohen (1988) defined a small effect as 0.20 , a medium effect as 0.50 , and a large effect as 0.80 . Cohen's analysis indicated that most effects reported in the psychological literature are small. The postidentification feedback effect in the current experiment was large for almost every measure. The overall effect of confirming feedback compared with no feedback on the confidence measure, for example, was $d=1.19$, a very large effect by conventional standards in the psychological literature. Perhaps a more meaningful way to express the power of the postidentification feedback effect is to examine the percentage of eyewitnesses who report confidence of $90 \%$ or greater as a function of feedback. In the no-feedback conditions, only $2 \%$ of the eyewitnesses reported that they were $90 \%$ or more confident at the time of their identification (and none of those eyewitnesses were $100 \%$ confident). In the confirmingfeedback conditions, in contrast, $23 \%$ reported being $90 \%$ or more confident at the time of their identification (and one third of those reported being $100 \%$ confident).

\section{Theoretical Implications}

From a theoretical perspective, we found no support for either enhancement or diminishment of the postidentification feedback effect as a function of delay. It is possible, of course, that the theoretical accounts of enhancement versus diminishment of the postidentification feedback effect as a function of delay were both correct and somehow canceled out each other. We find this to be quite unlikely, however, because the hypothesized processes for enhancement appear to us to be incompatible with the hypothesized processes for diminishment. Consider the process by which delayed feedback might have enhanced versus diminished the postidentification feedback effect. The enhancement hypothesis was that the original memory for the witnessing experience would become less accessible with time, resulting in greater impact for feedback. The diminishment hypothesis was that participantwitnesses would develop clearer thoughts for their witnessing experience with time, resulting in lesser impact for the feedback. The idea that both would occur and cancel out each other seems not to make sense.

It seems more parsimonious to assume that eyewitnesses have little or no directly accessible cognitive trace to how confident they were at the time of identification, how good their view was, how much attention they paid, and so on. In other words, postidentification answers to these questions are purely inferences that are constructed at the time that the measures are taken. Therefore, feedback influences this reconstruction regardless of whether the feedback is immediate or delayed and regardless of whether the measures are immediate or delayed. Although this seems like a radical conclusion, there are two additional empirical observations that seem to support it. First, participant-witnesses were asked whether they thought the feedback influenced their answers to the confidence question. Some said that they thought the feedback influenced their answers, and some said that it did not influence their answers. However, the actual effect was just as strong for those who said it did not influence their answers as it was for those who said it did influence their answers. This suggests that the witnesses did not develop thoughts about their experience at the time of the identification and that these thoughts were not constructed until the witnesses were asked the questions; otherwise, they would have been able to discern the effect of feedback.

Another result that is consistent with the idea that witnesses construct answers to the questions when asked, but have no accessible prefeedback trace, comes from the recent work of Semmler et al. (2002). After receiving confirming feedback or no feedback, participant-witnesses were asked either the usual retrospective confidence question ("How confident were you at the time you identified...") or were asked about their current confidence ("How confident are you right now...?"). In the confirming-feedback conditions, the average retrospective confidence score was 74.4, and the average current confidence score was 72.5 ; the difference between current and retrospective confidence was less than one tenth of a standard deviation. These nearly identical scores for current and retrospective confidence following feedback strongly suggest that eyewitnesses have no access to a prefeedback memory for their confidence and that current confidence guides eyewitnesses' assumptions about their prefeedback confidence. Ross (1989) suggested that when recalling one's standing on an attribute in the past, "the present serves as a benchmark because it is generally more salient and available than a person's earlier standing on an attribute" (p. 342). Along the same lines, Schwarz (1995) noted that numerous judgments, including memory judgments, are not based on all knowledge, but rather on a subset of knowledge that is most accessible at the time of judgment. Accessibility, in turn, is likely to be based on the construction of a mental model:

After learning the outcome, judges presumably update their mental models of the event in light of the outcome information, elaborate causal links that might have led up to the event, and de-emphasize information that seems irrelevant in light of the outcome (Sanna, Schwarz, \& Stocker, 2002, p. 497).

\section{Conclusions}

The confidence that eyewitnesses express in their identifications is a primary determinant of whether triers of fact will believe that the identification was accurate (e.g., Cutler et al., 1990; Fox \& Walters, 1986; Wells et al., 1981). "The logic of conducting a police lineup is to find out what the eyewitness knows about the identity of the culprit on the basis of the eyewitness's memory alone, without external factors influencing... how certain the eyewitness is" (Bradfield et al., 2002, p. 119). We observed very strong effects of postidentification feedback not only on eyewitness confidence but also other factors that are known to affect the perceived credibility of eyewitness identification testimony, such as how good the witness says his or her view was of the culprit and how much attention they were paying at the time (Bradfield \& Wells, 2000). Furthermore, we found no support for the contention that either delayed feedback or delayed measures moderates these very strong effects. Recommendations for double-blind lineup procedures and securing confidence statements at the time of the identification (prior to feedback) appear to be well-founded. 
An increasingly strong case seems to be emerging to suggest that eyewitnesses do not form clear impressions of how confident they were, how good their view was, how much attention they paid to the culprit, and so on, at the time that those events are actually happening. Instead, eyewitnesses construct impressions of these matters at a later time when they are asked retrospective questions about their witnessing experience. As a result, eyewitnesses' answers to such questions are strongly affected by postidentification feedback (present study; Bradfield et al., 2002; Wells \& Bradfield, 1998, 1999), their current feelings of confidence are nearly identical to their erroneous estimates of their prefeedback confidence (Semmler et al., 2002), and they appear to have no introspective awareness regarding whether their confidence has been influenced by feedback (present study; Wells \& Bradfield, 1998). There may be other levels at which one could explain these intriguing effects, but it seems to us that eyewitnesses' retrospective reports about the witnessing experience are almost purely postcomputations that are, therefore, highly malleable as a function of postidentification events.

\section{References}

Bradfield, A. L., \& Wells, G. L. (2000). The perceived validity of eyewitness identification testimony: A test of the five Biggers criteria. Law and Human Behavior, 24, 581-594.

Bradfield, A. L., Wells, G. L., \& Olson, E. A. (2002). The damaging effect of confirming feedback on the relation between eyewitness certainty and identification accuracy. Journal of Applied Psychology, 87, 112-120.

Chandler, C. C. (1991). How memory for an event is influenced by related events: Interference in modified recognition tests. Journal of Experimental Psychology: Learning, Memory, and Cognition, 17, 115-125.

Cohen, J. (1988). Statistical power analysis for the behavioral sciences (2nd ed.). Hillsdale, NJ: Erlbaum.

Cutler, B. R., Penrod, S., \& Dexter, H. R. (1990). Juror sensitivity to eyewitness identification evidence. Law and Human Behavior, 14, 185191.

Fox, S. G., \& Walters, H. A. (1986). The impact of general versus specific expert testimony and eyewitness confidence upon mock juror judgment. Law and Human Behavior, 10, 215-228.

Hoelzl, E., Kirchler, E., \& Rodler, C. (2002). Hindsight bias in economic expectations: I knew all along what I want to hear. Journal of Applied Psychology, 87, 437-443.

Louie, T. A. (1999). Decision makers' hindsight bias after receiving favorable and unfavorable feedback. Journal of Applied Psychology, 84, $29-41$.

Louie, T. A., Curren, M. T., \& Harich, K. R. (2000). "I knew we would win": Hindsight bias for favorable and unfavorable team decision outcomes. Journal of Applied Psychology, 85, 264-272.

Manson v. Braithwaite, 432 U.S. 98 (1977).

Neil v. Biggers, 409 U.S. 188 (1972).

Ross, M. (1989). The relation of implicit theories to the construction of personal histories. Psychological Review, 96, 341-357.

Sanna, L. J., Schwarz, N., \& Stocker, S. L. (2002). When debiasing backfires: Accessible content and accessibility experiences in debiasing hindsight. Journal of Experimental Psychology: Learning, Memory, and Cognition, 28, 497-502.

Schwarz, N. (1995). Social cognition: Information accessibility and use in social judgment. In E. E. Smith \& D. N. Osherson (Eds.), Thinking: An invitation to cognitive science (2nd ed., Vol. 3, pp. 345-376). Cambridge, MA: MIT Press.

Schwarz, N. (1999). Self-reports: How the questions shape the answers. American Psychologist, 54, 93-105.

Semmler, C., Brewer, N., \& Wells, G. L. (2002). Effects of postidentification feedback on eyewitness identification and nonidentification confidence. Manuscript submitted for publication.

Technical Working Group for Eyewitness Evidence. (1999). Eyewitness evidence: A guide for law enforcement. Washington, DC: U.S. Department of Justice.

Wells, G. L. (1993). What do we know about eyewitness identification? American Psychologist, 48, 553-571.

Wells, G. L., \& Bradfield, A. L. (1998). "Good, you identified the suspect": Feedback to eyewitnesses distorts their reports of the witnessing experience. Journal of Applied Psychology, 83, 360-376.

Wells, G. L., \& Bradfield, A. L. (1999). Distortions in eyewitnesses' recollections: Can the postidentification-feedback effect be moderated? Psychological Science, 10, 138-144.

Wells, G. L., Ferguson, T. J., \& Lindsay, R. C. L. (1981). The tractability of eyewitness confidence and its implication for triers of fact. Journal of Applied Psychology, 66, 688-696.

Wells, G. L., Olson, E. A., \& Charman, S. D. (2002). Eyewitness identification confidence. Current Directions in Psychological Science, 11, $151-154$.

Wells, G. L., Small, M., Penrod, S., Malpass, R. S., Fulero, S. M., \& Brimacombe, C. A. E. (1998). Eyewitness identification procedures: Recommendations for lineups and photospreads. Law and Human Behavior, 22, 603-647.

Windschitl, P. D. (1996). Memory for faces: Evidence of retrieval-based impairment. Journal of Experimental Psychology: Learning, Memory, and Cognition, 22, 1101-1122.

Received July 29, 2002

Revision received December 17, 2002

Accepted December 18, 2002

\section{E-Mail Notification of Your Latest Issue Online!}

Would you like to know when the next issue of your favorite APA journal will be available online? This service is now available to you. Sign up at http://watson.apa.org/ notify/ and you will be notified by e-mail when issues of interest to you become available! 